
\title{
R Research S Suare \\ Resilience and Coping Strategy after Abortion due to Fetal Malformation: A Web-Based Randomized Controlled Intervention
}

Maryam Zarei ( $\sim$ ma.zarei71@yahoo.com )

Iran University of Medical Sciences School of Nursing and Midwifery https://orcid.org/0000-00017028-5492

Masoomeh Kheirkhah

School of Nursing and Midwifery

Nemam Ali Azadi

School of public health

Mahdi Saberi

faculty member of tehran forensic medicine center

Nazanin Esmaeeli

master of clinical psychology

Research article

Keywords: Social Network Education, Resilience, Coping Strategy, Abortion, Abnormal Fetus

Posted Date: November 12th, 2020

DOI: https://doi.org/10.21203/rs.3.rs-103718/v1

License: (c) (1) This work is licensed under a Creative Commons Attribution 4.0 International License.

Read Full License 


\section{Abstract}

Background: Today, due to the development of advanced fetal screening techniques, termination for fetal abnormalities has increased, and has caused significant grief for women which can lead to long-term mental disorders. Self-help intervention with web guide may help provide appropriate education and counseling to women. Therefore, this study was conducted to determine the effect of social network education on resilience and coping strategies of women abortion due to fetal malformation.

Methods: This clinical trial studied two groups of 100 qualified pregnant women with abnormal fetuses who referred to Tehran Forensic Medicine Center. Randomly assigned into a randomized blocks list as two intervention group and routine group. Sampling was done by random allocation method by Excel software and blinding in the statistical analysis stage and was done as single-blind. The intervention in the experimental group was done as education through mobile social software (Soroush) and for 6 weeks and three times a week. The control group received routine care and after the second test, the content of the network education was also given to them. Resilience and coping strategies were evaluated before, immediately and three months after the intervention using the Persian version of Connor-Davidson Resilience Scale (CD-RISC-2003) and coping strategies (COPE-1989), respectively. Analysis of variance with repeated measures of ANOVA was used for statistical analysis.

Results: The mean resilience score in both control and test groups increased significantly $(P<0.001)$ which can indicate the effect of time, but the study of the effect of group over time indicated that in the resilience variable there was a significant difference between the two groups $(P<0.001)$. The simultaneous effect and group on the resilience variable was significant $(p<0.001)$ and the mean variation of resilience score in the intervention group was significantly higher than the control group $(p<0.001)$. The mean score of problem-focused coping strategies in the experimental group increased significantly during 12 weeks $(p<0.001$ ) but no significant difference was observed in the control group $(p=0.218)$. Regarding the emotion-focused strategy, a significant decrease was observed in the experimental group $(p<0.001)$ but in the control group there was a significant increase $(P=0.001)$. There was a significant decrease in the avoidance strategy in the experimental group $(p<0.001)$; there was no significant changes in the control group $(p=0.066)$ and the simultaneous effect of group and time in all coping strategies was significant $(P<0.001)$.

Conclusion: Social network education leads to enhanced resilience and greater use of problem-focused coping strategies in women after abortion due to fetal malformation and is effective on improving women's health by reducing emotion-focused and avoidance-focused coping strategies. Low cost and fast access to virtual mobile networks allow women to access educational content after abortion due to fetal malformation.

Registration in clinical trial: it is registered in the Thai Clinical Trial Registry (TCTR) under the number TCTR20200519001.

CONSORT : This study follows the CONSORT guidelines. 


\section{Background:}

Today, due to the development of advanced fetal screening techniques and increased reproductive age, chromosomal abnormalities and termination for fetal abnormalities have increased (1). According to United Nations population statistics, one of the seven most common causes of miscarriage around the world is fetal malformation. Numerous studies are conducted on the effects of abortion on mental disorders in different countries. Selective abortion can cause mental health disorders in the mother and family (2). Abortion is associated with an increase in a range of mental disorders including depression, anxiety, fear disorders, bipolar disorder, Post-Traumatic Stress Disorder (PTSD), stress and obsessive disorder $(3,4)$, and their quality of life, physical, emotional and social functioning is lower than normal population (5). Many women suffer from post-abortion issues such as avoiding re-pregnancy, fear of unhealthy fetus in the next pregnancy, not knowing the cause of the miscarriage, blaming themselves for the incidence of the event, feeling ashamed, guilty and frustrated (6). Maguire et al. (2015) know guilt, social isolation, skepticism in making decisions, insufficient partner support, low self-efficacy, younger age of parents, pregnancy progression and low social support among the predictors of poor prognosis in these women and have reported increased social support and elimination of misconceptions about the cause of anomalies to be effective in improving women's experiences and reducing their grief (7). The role of healthcare providers is important in facilitating this transition period (8).

The results of the Subramaney study, which examined the factors affecting depression and posttraumatic stress in women after abortion due to fetal malformation, showed that mother's age, termination time, chronic burden, religion and resilience have an effect on predicting depression scores and there is a significant relationship between resilience and depression and one of the suggested solutions is resilience education. Resilience is a concept that needs further research (9). Resilience helps to establish a bio-psychological balance in stressful situations and is the adaptive factor in adverse conditions, and leads to better coping, higher self-efficacy and less stress perception $(10,11)$; it gives people the power to cope with coming problems and provides the capacity of resistance against tensions and increases the ability to adapt and overcome danger and hardships (12). Resilience education program can, improve mental health, develop self-efficacy and the capacity of individuals for emotional regulation (13). Recent studies have suggested the implementation of resilience programs to improve mental health in individual, professional and organizational levels (13-15). Suspicious screening results have increased the psychological problems of pregnant women, and the lack of knowledge and skills of pregnant mothers in the face of these issues and problems is the main reason for the need to provide health, medical and psychological services to this group. One of the psychological services that is strongly associated with clinical therapies is the education of skills of coping with stress. Today, coping strategies in this group are studied from different angles (16). Coping is a set of behavioral and cognitive activities and processes to prevent, manage and reduce stress. In fact, stress as a psychological phenomenon is one of the important factors in the occurrence and persistence of many mental disorders (17), and it's found that the use of effective coping strategies, plays an important role in reducing the formation and persistence of stressful events such as abortion. Adopting appropriate strategies of coping with stress can reduce its negative effects on mental health and lead to greater adjustment (18). Coping 
strategies are cognitive-behavioral measures used by a person to manage his or her desires in stressful and difficult situations. Coping efforts help the individual to correct behavior or reduce negative emotions (19). Coping efforts include using problem-focused coping, emotion-focused coping, and avoidantfocused coping in stressful situations. Problem-focused coping is a method used to change or manage stressful situations, and emotion-focused coping is a method used to control emotional reactions related to the stressful factor. The avoidance-focused approach counteracts the objective distance from the stressor and the denial (mental distance) of the stressor (20). The effect of these strategies is temporary and in the long run will cause stress and tension in the person. Problem-focused and rational coping strategies can have a positive effect on people's mental health and can be taught and learned (21).

It should be noted that so far few intervention studies are conducted in the field of abortion due to fetal malformation $(7,22,23)$. lee Eleanor et al. (2016) with a systematic review of web-based interventions in the prevention and treatment of perinatal mental disorders, studied therapeutic interventions from the beginning of pregnancy to one year after delivery and the results showed that providing services through the Internet can be an available, practical, effective and cost-effective solution for the treatment and prevention of perinatal mental disorders in pregnant women. But further researches in this regard is known to be necessary (24). Swanson emphasizes midwifery counseling after an abortion (25). Many studies consider educational supportive intervention after abortion due to fetal malformation necessary and recommend further researches into the knowledge of how to care for these women and recognize referring of these patients to interdisciplinary teams as an effective strategy to address the intra- and postoperative care gap after the abortion $(26,27)$. There are various methods to provide educational support and counseling to these women to meet their needs, including face-to-face education, multimedia education and social network education, but according to recent studies, we decided to use social network education. The results of a systematic review of Bagheri et al. (2020) showed that there are very few studies on social network education and counseling in abortion (28), and the results of a study that examined the help-seeking behaviors of these women showed that family, friends, colleagues, genetic counselors, psychologists and gynecologists are the source of these mothers' referrals, but due to the advancement of technology, $65 \%$ of these women have used the Internet as a helpful source and received their sensitive health issues anonymously, and have emphasized the high potential of online support in these women (1). Today, using mobile technologies available to patients and healthcare professionals, it is possible to provide the necessary support to patients to acquire self-management skills (29). Given that no study is conducted on the effect of virtual learning on resilience and coping skills of women with abortion due to fetal malformation, the present study is designed and implemented to determine the effect of social network education on resilience and coping strategies of women after abortion due to fetal malformation.

\section{Method:}

The present study is a randomized controlled trial of parallel type and the inclusion criteria are: having a license for abortion due to fetal malformation, literacy, having no history of known mental illness, none use of psychiatric drugs, lack of any event that caused grief, anxiety and depression, such as the death of 
loved ones, etc. in the last 2 months, having no history of infertility and having a smart phone, and the exclusion criteria are: refusal of participating in the study, pregnancy during the study, the occurrence of an accident in a person's life during the study, lack of feedback to the content of social network education for more than two sessions, the use of consulting services outside the research during the study process.

The sample size was determined to be 100 by considering $0.05 \%$ type I error, Type II error $\beta=0.2$ and the drop level of $20 \%$. Participants were registered by a forensic researcher midwife from qualified clients and sampling was continuous. Randomization was done with Excel software by an IT expert colleague in advance and the sample allocation table was prepared and the samples were allocated into two groups of intervention $(n=50)$ and control $(n=50)$.

Sampling of women referring to Tehran Forensic Medicine Center was done in the fall of 2019 and data collection was done through an electronic questionnaire in the virtual space of Soroush mobile phone software. Informed and free written consent to participate in the study was completed in the first face-toface meeting at the forensic medicine center, then the participants received the telephone number of the researcher midwife and contacted the midwife after the abortion and all the participants first completed pre-test questionnaires. Evaluation of samples was done in three times: first, for pre-test for both groups, electronic questionnaires of personal information (age, occupation, education, place of residence, etc.) and midwifery (number of pregnancies, number of children, week of pregnancy, cause of fetal malformation, family history, termination method, place of abortion, etc.) were sent and completed, and both groups were evaluated in terms of coping strategies with Conner-Davidson Resilience Scale (CD-RIS) and in terms of coping strategies with the Cope Operation Preference Enquiry (COPE) (1989) and the scores were considered as a pre-test. The CD-RIS consists of 25 questions that are scored on a Likert scale between zero (completely incorrect) to five (always correct). Test scores range from zero to 100 . Higher scores indicate more resilience of the subject. Connor and Davidson reported a Cronbach's alpha coefficient of the Resilience Scale of $89 \%$. Also, the reliability coefficient obtained from the re-test method in a 4-week interval was reported to be $87 \%$ (30). This scale is standardized in Iran by Mohammadi (2005) (31). In a study conducted by Samani et al. among students, their reliability was reported to be 0.93 and validity (by factor analysis method and convergent and divergent validity) was achieved by test constructors in different normal and at-risk groups (32). The COPE was developed by Carver et al. in 1989 and was designed to examine the Lazarus model of stress and the self-regulation and behavioral adjustment model (33). This enquiry was translated for the Iranian population in 1992 by Zolfaghari et al. (34). It includes 60 questions and three general categories, which are: problem-focused coping, emotionfocused coping, and inefficient and ineffective coping, each of which has 20 questions. This questionnaire is a self-report tool and is set in a four-point Likert scale from never (score one) to high (score four); the sum of scores in each of the scales is considered as a measure of the use of that coping strategy. This questionnaire does not have a total score (33). Differential validity of this test has been reported with structures such as toughness, optimism, control and strong self-confidence. The reliability coefficient of the whole test using Cronbach's alpha method in the study of Mollazadeh, which was performed on 422 people in the age range of 18 to 34 years, is reported to be 0.83 by Cronbach's alpha 
method (35). Due to the fact that the validity and reliability of COPE adjustment and coping tools in Iran is reviewed and confirmed, no reassessment was performed in the present study.

The educational content chapter, which was compiled and developed by the research team (consisting of a doctor of medical and midwifery education, a psychiatrist, a master of clinical psychology, and a master of counseling in midwifery), includes information about abortion and the care after that, the necessary care and education for re-pregnancy, skills to increase resilience and problem-focused coping skills, anger management skills, courage skills, investigating the causes of fetal abnormalities, the prevalence of fetal abnormalities and the possibility of recurrence, ways to prevent fetal abnormalities, ways of screening and diagnosis of fetal abnormalities (first trimester screening, second trimester screening, cell free DNA, amniocentesis, Chorionic Villi Sampling (CVS), contraceptive selection counseling that is listed in table number one for each session.

The intervention in the experimental group was presented by the researcher (consulting midwife) as a social network education in Soroush social network and three times a week for six weeks. The content of the education was sent to each participant in the form of clear, legible and attractive messages along with related images and videos, in such a way that the content was sent to them first and then enough time was given to the individual to observe and think about it and to perform the embedded tasks in order to consolidate and support the techniques and educational materials, discuss and exchange views and questions and answers with the consulting midwife, and this interactive relationship lasts up to six weeks and three times a week after the abortion due to fetal malformation. In addition to national routine care, the experimental group also underwent educational supportive intervention by the researcher. The control group did not receive any intervention in the study process, but only received routine healthcare, and the researcher sent them breast and cervical screening files to keep in touch, and morally and to benefit from the study, after completing the questionnaires in the second stage, the content of the sessions was virtually provided to the control group. Post-test was performed twice ( 6 weeks later and 12 weeks later) for both groups with electronic resilience questionnaires and coping strategies. The groups were analyzed as intra- and inter-group with each other using SPSS-16 software and Chi-square, Mann-Whitney, independent t-test and analysis of variance with repeated measures of ANOVA with a significance level of 0.05 . 
Table 1

Social network education program for 6 weeks (three times a week)

\section{Week Educational content}

Homework

Frist Welcoming, expressing the goals and topics, information about abortion and its physical complications, the time to start sexual intercourse, asking questions about patients' concerns and ambiguities and resolving them as much as possible

Emotional evacuation, self-awareness skills, teaching the correct methods of emotional evacuation, assessment of cognitive errors

Relaxation skills (with music), diaphragmatic breathing techniques, anxiety and stress management techniques

- Practicing progressive relaxation technique

- Reviewing stress and discussing it and finding answers to it at home

Second Reviewing homework and reviewing the previous week, defining grief and its steps, coping strategies

Defining coping and its types, problem solving skills education

Anger control skills education, courage education skills

When was the last time you became angry, write down your reaction.

Third Definition of resilience

What do you think are the characteristics of resilient people? Please write down your answer.

Characteristics of resilient individuals: (conscious acceptance, acceptance of barriers, sources of internal control, problem solving, strong social relationships, lack of self-assessment, request for timely assistance)

Four main characteristics of resilient people from a psychological perspective: (feeling of worth, problem-solving skills, social adequacy, optimism and empathy)

Fourth Educating resilience strategies: (having meaning and purpose, developing communication, flexibility to change, nutrition and healthcare)

Continuing education resilience strategies: (Educating healthy skills to deal with problems, educating positive emotionfocused coping skills and problem-focused coping skills)

Name a stressful event that triggers your emotions and write down your feelings about that event.

Continuing the provision of solutions to create resilience: (optimism, creating positive attachments, strengthening spirituality), summarizing and reviewing resilience education 


\begin{tabular}{|ll|}
\hline Week & Educational content \\
\hline Fifth & $\begin{array}{l}\text { Defining and investigating the causes of abnormalities in the } \\
\text { fetus, the prevalence of fetal abnormalities and the possibility } \\
\text { of recurrence, ways to prevent the occurrence of abnormalities } \\
\text { in the fetus }\end{array}$ \\
& $\begin{array}{l}\text { Ways of screening and diagnosis of fetal abnormalities: (first } \\
\text { trimester screening, second trimester screening, cell free DNA, } \\
\text { amniocentesis, Chorionic Villi Sampling (CVS) }\end{array}$ \\
\hline Sixth & $\begin{array}{l}\text { Advice on choosing a contraceptive method } \\
\text { Necessary preparations for re-pregnancy, review of previous }\end{array}$ \\
& $\begin{array}{l}\text { Answering questions } \\
\text { Run the post-test and complete the education program }\end{array}$ \\
\hline
\end{tabular}

\section{Results:}

Six weeks after the study, two individuals in the control group and two in the experimental group did not respond to the messages, and finally 48 people remained in each group. Shapiro-Wilk test was used to evaluate the normality of the data (quantitative variables) and a significance level of $(p<0.05)$ was considered (Table 1); variables of women's age, emotion-focused strategy score and inefficient strategy score at the beginning of the study and week 6 of data distribution was normal in the experimental and control groups and it was abnormal in the form of data distribution for at least one of the groups. Nonparametric tests were used to test and compare the groups. Information about the demographic characteristics of the samples showed that the two experimental and control groups were homogeneous in terms of demographic characteristics $(p<0.05)$. (Table number three - Appendix). 
Table 2

Shapiro-Wilk test result to investigate the normality of the distribution of quantitative variables

\begin{tabular}{|c|c|c|c|c|}
\hline \multirow[t]{2}{*}{ Variable } & \multirow{2}{*}{$\begin{array}{l}\text { Test } \\
\text { group } \\
\mathrm{P}- \\
\text { value }\end{array}$} & \multirow[t]{2}{*}{$\begin{array}{l}\text { Normal } \\
\text { distribution }\end{array}$} & $\begin{array}{l}\text { Control } \\
\text { group }\end{array}$ & \multirow[t]{2}{*}{$\begin{array}{l}\text { Normal } \\
\text { distribution }\end{array}$} \\
\hline & & & P-value & \\
\hline Woman's age & 0.103 & प & 0.398 & प \\
\hline Spouse's age & $<.001$ & प & 0.001 & ૫ \\
\hline Number of pregnancies & $\begin{array}{l}< \\
0.001\end{array}$ & प & $<0.001$ & प \\
\hline Number of children & $<.001$ & प & $<0.001$ & प \\
\hline Number of abortions & $<.001$ & Q & $<0.001$ & प \\
\hline $\begin{array}{l}\text { Week of diagnosis of the fetal } \\
\text { malformation }\end{array}$ & $<0.001$ & 0 & $<0.001$ & प \\
\hline $\begin{array}{l}\text { Week of abortion due to fetus } \\
\text { malformation }\end{array}$ & $\overleftarrow{0} .001$ & प & $<0.001$ & प \\
\hline Duration of abortion & $<0.001$ & Q & $<0.001$ & प \\
\hline $\begin{array}{l}\text { Duration of consultation by the abortion } \\
\text { therapist }\end{array}$ & $<.001$ & प & $<0.001$ & प \\
\hline Score of resilience before the study & $<.001$ & ( & $<0.001$ & प \\
\hline Score of resilience in 6 weeks later & 0.146 & प & $<0.001$ & प \\
\hline Score of resilience in 12 weeks later & 0.003 & प & $<0.001$ & प \\
\hline $\begin{array}{l}\text { Problem-focused strategy score in the } \\
\text { pre-study }\end{array}$ & 0.002 & प & 0.004 & ( \\
\hline $\begin{array}{l}\text { Problem-focused strategy score in } 6 \\
\text { weeks later }\end{array}$ & 0.662 & 0 & 0.006 & प \\
\hline $\begin{array}{l}\text { Problem-focused strategy score in } 12 \\
\text { weeks later }\end{array}$ & 0.330 & प & 0.005 & ૫ \\
\hline $\begin{array}{l}\text { Emotion-focused strategy score before } \\
\text { the study }\end{array}$ & 0.495 & Q & 0.217 & प \\
\hline $\begin{array}{l}\text { Emotion-focused strategy score in } 6 \\
\text { weeks later }\end{array}$ & 0.343 & Q & 0.178 & ૫ \\
\hline
\end{tabular}




\begin{tabular}{|c|c|c|c|c|}
\hline \multirow[t]{2}{*}{ Variable } & $\begin{array}{l}\text { Test } \\
\text { group }\end{array}$ & \multirow[t]{2}{*}{$\begin{array}{l}\text { Normal } \\
\text { distribution }\end{array}$} & $\begin{array}{l}\text { Control } \\
\text { group }\end{array}$ & \multirow[t]{2}{*}{$\begin{array}{l}\text { Normal } \\
\text { distribution }\end{array}$} \\
\hline & $\begin{array}{l}\mathrm{P}- \\
\text { value }\end{array}$ & & P-value & \\
\hline $\begin{array}{l}\text { Emotion-focused strategy score in } 12 \\
\text { weeks later }\end{array}$ & 0.007 & प & 0.332 & प \\
\hline $\begin{array}{l}\text { Inefficient strategy score before the } \\
\text { study }\end{array}$ & 0.344 & Q & 0.567 & प \\
\hline $\begin{array}{l}\text { Inefficient strategy score in } 6 \text { weeks } \\
\text { later }\end{array}$ & 0.066 & Q & 0.208 & प \\
\hline $\begin{array}{l}\text { Inefficient strategy score in } 12 \text { weeks } \\
\text { later }\end{array}$ & 0.015 & 0 & 0.245 & Q \\
\hline
\end{tabular}

Univariate and multivariate tests were used to investigate the interaction between time and the usual group. The equality of variance of the groups was checked by the box's $M$ test and the sphericity of the observations was evaluated by the Mauchly test. Equality of the variances was met for all the areas. In the multivariate test, Pillai - Bartlett statistic was used to examine the interaction. The assumption of the sphericity was not confirmed by Mauchly test and the Greenhouse - Geisser correction was used. The significance of univariate and multivariate test results (at the level of $0.05 / 2=0.025$ ) is shown in Table 3 and there was an interaction effect between resilience and domains of adjustment and coping and the trend of changes over time depended on the intervention group.

Table 3

Univariate and multivariate test results to evaluate the "time $\times$ group" interaction for resilience and areas of coping

\begin{tabular}{|llllll|}
\hline & Multivariate & & & Univariate \\
& Pillai's trace & F & P value & F & P value \\
\hline Resilience & .723 & 121.19 & $<0.001$ & 234.133 & $<0.001$ \\
\hline Problem-focused coping & 0.900 & 418.597 & $<0.001$ & 541.29 & $<0.001$ \\
\hline Emotion-focused coping & 0.281 & 18.202 & $<0.001$ & 28.565 & $<0.001$ \\
\hline Avoidance coping & 0.940 & 724.88 & $<0.001$ & 785.64 & $<0.001$ \\
\hline
\end{tabular}

Due to the significant interactions, analysis and comparison were performed at each time point (at the beginning of the study, 6 weeks and 12 weeks, and for each group, changes over time were tested).

To evaluate the resilience score and each of the areas of adjustment and coping between the two groups, analysis of variance was performed at the beginning of the study, 6 weeks, and 12 weeks later. To prevent 
the increase of the first type error, Bonferroni correction was used and the significance level of $5 \%$ was decreased to $0.017(0.05 / 3=0.017)$. At the beginning of the study, the difference between the groups was not significant, but in 6 weeks and 12 weeks after the intervention, the mean resilience and all areas of adjustment in the two groups were significantly different. The results are shown in Table 4.

Table 4

Results of one-way analysis of variance to examine the difference between resilience and each of the areas of adjustment and coping between groups in each of the time points studied

\section{Time}

\section{Before the intervention}

Resilience

$F(1,94)$

0.726

0.396

0.780

119.305

Problemfocused

$F(1,94)$

0.379

$<0.001$

$<0.001$

\section{2 weeks after the intervention}

89.46

$<0.001$

P-value

Emotion-

0.780

84.545

67.858

focused

$F(1,94)$

0.379

$<0.001$

$<0.001$

P-value

Avoidance coping

0.435

81.365

104.978

$F(1,94)$

0.511

$<0.001$

$<0.001$

P-value

0.726

69.82

89.46

To examine whether there has been a change in resilience, problem-focused coping, emotion-focused coping, and avoidance coping of participants over time (trend), trend, univariate, and multivariate tests were done for each group using $\mathrm{T}^{2}$ hotelling statistics. And to prevent the increase of the first type error, the significance level was reduced from $5 \%$ to $0.017\left(0.05 /\left(3^{\star} 1\right)=0.017\right)$. The results are given in Table 5 . 
Table 5

Univariate and multivariate test results using $\mathrm{T}^{2}$ hoteling statistics to examine the trend of changes in resilience score and each of the areas of adjustment and coping by study groups.

\section{Test groups}

\section{Experimental}

\section{Resilience}

Univariate

Multivariate ( $T^{2}$ Hotelling)

$$
F(2,46)=315.08, P<0.001
$$

$\mathrm{F}(1.22,57.26)=469.28, \mathrm{P}<$ 0.001

\section{Problem-focused}

Univariate

Multivariate $\left(\mathrm{T}^{2}\right.$

Hotelling)

\section{Emotion-focused}

Univariate

$$
F(2,46)=55.40, P<0.001
$$

$\mathrm{F}(1.121,52.68)=74.20, \mathrm{P}<$

Multivariate $\left(T^{2}\right.$

Hotelling) 0.001

\section{Control}

\section{Avoidance coping}

Univariate

$F(2,46)=481.84, P<0.001$

$F(2,46)=258.96, P<0.001$

Multivariate $\left(T^{2}\right.$

Hotelling)

$F(2,46)=334.11, P<0.001$

$F(90.37,9.62)=441.31, P<0.001$
$F(1480.66,80)=869.89,. P<0.001$

$F(2,46)=154.8, P<0.001$

$F(3869.38,659.94)=275.57, P<$ 0.001
$F(165.29,29.37)=264.46, P<0.001$ 0.001 
Table 6

Comparison of resilience and coping strategies before, 6 and 12 weeks after the intervention in experimental and control groups in women after abortion due to fetal malformation

\begin{tabular}{|c|c|c|c|c|c|c|c|}
\hline \multirow[t]{2}{*}{ Variable } & \multirow[t]{2}{*}{ Group } & \multirow{2}{*}{$\begin{array}{l}\text { Before } \\
\text { Mean } \\
\pm \text { S.D }\end{array}$} & \multirow{2}{*}{$\begin{array}{l}6 \\
\text { weeks } \\
\text { later } \\
\text { Mean } \\
\pm \text { S.D }\end{array}$} & \multirow{2}{*}{$\begin{array}{l}12 \\
\text { weeks } \\
\text { later } \\
\text { Mean } \pm \\
\text { S.D }\end{array}$} & \multicolumn{3}{|c|}{$p$-value } \\
\hline & & & & & $\begin{array}{l}\text { Time } \\
\text { factor }\end{array}$ & $\begin{array}{l}\text { Time } \\
\text { factor } \\
\text { xgroup }\end{array}$ & $\begin{array}{l}\text { Group } \\
\text { factor }\end{array}$ \\
\hline \multirow[t]{3}{*}{ Resilience } & Experimental & $\begin{array}{l}45.29 \\
\pm 8.40\end{array}$ & $\begin{array}{l}62.41 \\
\pm 5.78\end{array}$ & $\begin{array}{l}67.87 \pm \\
5.66\end{array}$ & \multirow[t]{3}{*}{$<.001$} & \multirow[t]{3}{*}{$<0.001$} & \multirow[t]{3}{*}{$<0.001$} \\
\hline & Control & $\begin{array}{l}46.75 \\
\pm 8.36\end{array}$ & $\begin{array}{l}50.16 \\
\pm 8.34\end{array}$ & $\begin{array}{l}54.58 \pm \\
7.91\end{array}$ & & & \\
\hline & $\begin{array}{l}\text { Mann- } \\
\text { Whitney }\end{array}$ & 0.168 & $<0.001$ & $<0.001$ & & & \\
\hline \multirow[t]{3}{*}{$\begin{array}{l}\text { Problem-focused } \\
\text { strategy }\end{array}$} & Experimental & $\begin{array}{l}45.60 \\
\pm 5.60\end{array}$ & $\begin{array}{l}60.10 \\
\pm 5.73\end{array}$ & $\begin{array}{l}57.79 \pm \\
4.91\end{array}$ & \multirow[t]{3}{*}{0.218} & \multirow[t]{3}{*}{$<0.001$} & \multirow[t]{3}{*}{$<0.001$} \\
\hline & Control & $\begin{array}{l}46.60 \\
\pm 5.48\end{array}$ & $\begin{array}{l}47.66 \\
\pm 5.41\end{array}$ & $\begin{array}{l}48.54 \pm \\
5.33\end{array}$ & & & \\
\hline & $\begin{array}{l}\text { Mann- } \\
\text { Whitney }\end{array}$ & 0.278 & $<0.001$ & $<0.001$ & & & \\
\hline \multirow[t]{3}{*}{$\begin{array}{l}\text { Emotional } \\
\text { focused strategy }\end{array}$} & Experimental & $\begin{array}{l}55.89 \\
\pm 3.59\end{array}$ & $\begin{array}{l}50.58 \\
\pm 3.24\end{array}$ & $\begin{array}{l}52.10 \pm \\
3.50\end{array}$ & \multirow[t]{3}{*}{0.001} & \multirow[t]{3}{*}{$<0.001$} & \multirow[t]{3}{*}{$<0.001$} \\
\hline & Control & $\begin{array}{l}55.18 \\
\pm 3.54\end{array}$ & $\begin{array}{l}57.22 \\
\pm 5.53\end{array}$ & $\begin{array}{l}57.93 \pm \\
3.42\end{array}$ & & & \\
\hline & $\begin{array}{l}\text { Mann- } \\
\text { Whitney }\end{array}$ & 0.333 & $<0.001$ & $<0.001$ & & & \\
\hline \multirow[t]{3}{*}{$\begin{array}{l}\text { Inefficient } \\
\text { strategy test }\end{array}$} & Experimental & $\begin{array}{l}37.37 \\
\pm 5.81\end{array}$ & $\begin{array}{l}29.72 \\
\pm 4.91\end{array}$ & $\begin{array}{l}28.31 \pm \\
3.95\end{array}$ & \multirow[t]{3}{*}{0.06} & \multirow[t]{3}{*}{$<0.001$} & \multirow[t]{3}{*}{$<0.001$} \\
\hline & Control & $\begin{array}{l}36.60 \\
\pm 5.63\end{array}$ & $\begin{array}{l}39.20 \\
\pm 5.36\end{array}$ & $\begin{array}{l}38.18 \pm \\
5.38\end{array}$ & & & \\
\hline & $\begin{array}{l}\text { Mann- } \\
\text { Whitney }\end{array}$ & 0.511 & $<0.001$ & $<0.001$ & & & \\
\hline
\end{tabular}

The results of analysis of variance with repeated measures showed that the mean score of problemfocused strategy in the experimental group before the intervention to 6 weeks later and 12 weeks later was statistically significant and increasing $(p<0.001)$, but from 6 weeks later, at the same time with the completion of the social network education, compared to 12 weeks later, the mean score of problemfocused strategy in the experimental group was stable and there was no significant difference. In the control group, the mean score of problem-focused strategy at different times was not significantly 
different $(P=0.218)$ and there was no change in the score of the problem-focused strategy of this group. Comparison of the results of the two groups based on Mann-Whitney test showed that in the pre-test stage the mean score of the problem-focused strategy was not statistically significant $(p=0.287)$ and the groups were homogeneous, but in the stage of 6 weeks after and 12 weeks after the study, there was a significant difference $(P<0.001)$.

The mean score of emotion-focused strategy with analysis of variance with repeated measures in the experimental group in the pre-intervention times to 6 weeks later and 12 weeks later was statistically significant $(p<0.001)$ and had a decreasing trend. The control group also had a statistically significant difference $(p=0.001)$ and an increasing trend in the mean score of emotion-focused strategy at different times. Comparison of the results of the two groups based on independent $t$-test showed that in the pretest stage the mean score of emotion-focused strategy was not statistically significant $(p=0.333)$ and the two groups were homogeneous, but in 6 weeks and 12 weeks after the study there was a significant difference $(P<0.001)$, and the score of emotion-focused strategy in the experimental group was lower than the control group.

The mean score of inefficient strategy with repeated measures analysis of variance test in the experimental group had a significant difference in the time before the intervention to 6 and 12 weeks later $(p<0.001)$ and had a decreasing trend, while In the control group, the mean score of inefficient strategy at different times was not statistically significant $(p=0.066)$ and there was no change in the score of inefficient strategy in this group. Comparison of the results of the two groups based on independent $t$-test showed that in the pre-test stage the mean score of the inefficient strategy was not statistically significant $(p=0.287)$ and the groups were homogeneous, but at 6 weeks and 12 weeks after the study there was a significant difference between the groups $(P<0.001)$.

\section{Discussion:}

The aim of this study was to examine the effect of social network education on resilience and coping strategies of women after abortion due to abnormal fetal abnormalities. The results in the effect of social network education on resilience of women after abortion due to fetal malformation showed that social network education led to increased resilience in the group of women in the experimental group more than before the intervention. This findings were consistent with the results of the researches by Shalkoohi, Afshari, Seyed Fatemi et al. (36-38), and results of the researches by Sriarporn, Heler, Lee, Kersting, Fanseca, Johnson, Bagheri, Golmakani, Haj Nasiri et al. (24, 39-45)

who studied the effect of specific education on the improvement of mental states after giving up pregnancy. Explaining the significant increase in resilience in the control group after 12 weeks from the beginning of the study, it can be said that over time, the rate of psychological complications after abortion decreases, such as anxiety. But it's declining is faster in people who are consulted and followed up. Therefore, these people can achieve mental health before the abortion. Almost all studies have proven the existence of psychological complications after abortion, but the rate of reduction of psychological 
complications after abortion is reported differently over time after the abortion (46) and it was consistent with the research of Heler, Haj Nasiri et al. $(40,45)$ in which the results showed that in the control group, significant improvement was made in the mental states of women after abortion. The trend of improvement in women who had received education and consult was faster. In explaining this finding, it can be said that due to the fact that abortion due to fetal malformation is one of the factors threatening the physical and mental health of women, causes them to endure a lot of stress, sadness and grief and suffer in effective adjustment and coping. The researches have consistently shown that people with positive resilience-related traits are able to manage and overcome the unfortunate problems of life (47) so by increasing women's support and awareness of abnormal fetuses, and screening and diagnostic methods, post-abortion care, contraceptive methods, and resilience skills education, it may lead to reduced stress and increased quality of life associated with improving their resilience, which is effective on both their mental health and the process of physical recovery and helps for the preparation for repregnancy. In the meantime, social network education is one of the best strategies that can increase the level of awareness of women and provide them with the necessary information. The results of studies by Eleanor, Kersting, Fanseca et al. showed the positive effect of web-based education on the improvement of the mental state of women in the prenatal period, which is consistent with the present study $(24,41$, 42). An up-to-date and accessible social network education method is effective in reducing the costs imposed on the family and the healthcare system and can be provided as an effective and efficient method for women after abortion due to fetal malformations.

The results of examining the effect of social network education on women's coping strategies after abortion due to fetal malformation showed that social network education has increased problem-focused strategy in women in the experimental group and decreased emotion-focused strategy and inefficient strategy in them. These findings are consistent with the findings of Mr. Miri and Mr. Niknam, Haghayegh et al. $(48,49)$ and show that educating problem-solving skills reduces decision-making doubts and reduces the inability to cope with the problems of everyday life. Considering that some problem-solving approaches to stress management (becoming aware of stressors), structuring (gathering data on stressors and inquiring about available support resources) and skills (self-expression and intimacy) are effective in reducing or eliminating the unpleasant consequences of stress and try to overcome the stressor factor so that, problem-solving method could be used in stressor situations (50). However, in the control group, there was no significant change in the problem-focused and inefficient strategy and an increase in the emotion-focused strategy was observed, which can be explained that the control group further moved towards emotion-focused coping strategies to cope and adjust with abortion over time. However, because the level of family support for mothers after abortion varies from family to family, and this can affect the degree and severity of resilience and coping strategies, which is one of the limitations of this study which was out of the researcher's control.

\section{Conclusion:}

Providing social network education and counseling after abortion due to fetal malformation is very effective in increasing resilience and using problem-focused coping strategies and reducing inefficient 
and emotion-focused coping behaviors. Healthcare providers, especially midwives, can reduce the level and severity of psychological complications after medical abortion by providing social network education and counseling and identifying women at risk, and can play a significant role in improving the health of women and society. This low cost and available intervention, and in the present era, with the rapid access of people to virtual networks, the content of this educational program can be widely used for women after abortion due to fetal malformation.

\section{Declarations:}

\section{Ethics approval and consent to participate:}

This study was registered in the ethics committee of the School of Nursing and Midwifery of Iran University of Medical Sciences under the number IR.IUMS.REC.1398.172 and informed consent was received from all participants before the study, which was in writing and in person at the first meeting for sampling.

\section{Consent for publication:}

Not Applicable

\section{Availability of data and material:}

The data sets generated and/or analyzed during the present study are not publicly available for some reason, but the data are available in encrypted form at the request of the author.

\section{Competing interests:}

There is no conflict of interest for the authors of this article.

\section{Funding:}

The financial resources of this research were provided by Iran University of Medical Sciences.

\section{Authors' contributions:}

all authors have read and approved the manuscript

M. Kh: Monitoring the research process and article and participation in writing the content of the intervention

M. Z: Write a proposal \& article, collect research samples and participate in writing the content of the intervention

N.A: Data analysis 
M.S: Consultation at a forensic center

N.A: Advice on writing intervention psychology content

\section{Acknowledgements:}

This article is a part of the master's thesis in midwifery counseling and research project with the number 98-1-3-14465 School of Nursing and Midwifery, Iran University of Medical Sciences. Dear officials and professors of Iran University of Medical Sciences and Forensic Medicine Center of Tehran Province and pregnant women participating in the study who made the research possible, are thanked and appreciated.

\section{References:}

1. Hanschmidt F, Hoffmann R, Klingner J, Kersting A, Stepan H. Help-seeking Following Termination of Pregnancy after Diagnosis of Fetal Anomaly: Women's Intentions and Experiences 1 to 7 Years after the Event. Geburtshilfe und Frauenheilkunde. 2018;78(02):160-6.

2. Khouzam H. Could Elective Abortion Precipitate Mental Health Consequences in its Recipients and Providers. Journal of Depression and Anxiety. 2015;4:196.

3. Coleman PK, Coyle CT, Shuping M, Rue VM. Induced abortion and anxiety, mood, and substance abuse disorders: Isolating the effects of abortion in the national comorbidity survey. Journal of psychiatric research. 2009;43(8):770-6.

4. Steinberg JR. Later abortions and mental health: psychological experiences of women having later abortions-a critical review of research. Women's Health Issues. 2011;21(3):S44-S8.

5. Nansel TR, Doyle F, Frederick MM, Zhang J. Quality of life in women undergoing medical treatment for early pregnancy failure. Journal of Obstetric, Gynecologic, \& Neonatal Nursing. 2005;34(4):47381.

6. Slobodin 0. The aborted time: a temporal view on the trauma of pregnancy loss. Journal of Depression and Anxiety. 2014;3(04):2167-1044.1000163.

7. Maguire M, Light A, Kuppermann M, Dalton VK, Steinauer JE, Kerns JL. Grief after second-trimester termination for fetal anomaly: a qualitative study. Contraception. 2015;91(3):234-9.

8. Howard ED. Family-centered care in the context of fetal abnormality. The Journal of perinatal \& neonatal nursing. 2006;20(3):237-42.

9. Subramaney U, Wyatt GE, Williams JK, Zhang M, Liu HH, Chin D. Depressive and post-traumatic stress symptoms following termination of pregnancy in South African women: A longitudinal study measuring the effects of chronic burden, crisis support and resilience. South African Medical Journal. 2015;105(11):934-8.

10. Major B, Richards C, Cooper ML, Cozzarelli C, Zubek J. Personal resilience, cognitive appraisals, and coping: an integrative model of adjustment to abortion. Journal of personality and social psychology. 1998;74(3):735. 
11. Waller MA, Okamoto SK. Resiliency factors related to substance use/resistance: Perceptions of Native adolescents of the Southwest. J Soc \& Soc Welfare. 2003;30:79.

12. Bagheri Zanjani Asl Monfared L, Entesar Foumany G. The effectiveness of group based hope-therapy on increasing resilience and hope in life expectancy in patients with breast cancer. Journal of Health Promotion Management. 2016;5(4):56-62.

13. Foster K, Roche M, Delgado C, Cuzzillo C, Giandinoto JA, Furness T. Resilience and mental health nursing: An integrative review of international literature. International journal of mental health nursing. 2018;28(1):71-85.

14. Guo Yf, Plummer V, Lam L, Wang Y, Cross W, Zhang Jp. The effects of resilience and turnover intention on nurses' burnout: Findings from a comparative cross-sectional study. Journal of clinical nursing. 2019;28(3-4):499-508.

15. Smith GD, Yang F. Stress, resilience and psychological well-being in Chinese undergraduate nursing students. Nurse education today. 2017;49:90-5.

16. Lafarge $\mathrm{C}$, Mitchell K, Fox P. Posttraumatic growth following pregnancy termination for fetal abnormality: the predictive role of coping strategies and perinatal grief. Anxiety, Stress, \& Coping. 2017;30(5):536-50.

17. Lau Y, Wang Y, Kwong DHK, Wang Y. Testing direct and moderating effects of coping styles on the relationship between perceived stress and antenatal anxiety symptoms. Journal of Psychosomatic Obstetrics \& Gynecology. 2015;36(1):29-35.

18. Paternoster R, Jaynes CM, Wilson T. Rational choice theory and interest in the "Fortune of Others". Journal of research in crime and delinquency. 2017;54(6):847-68.

19. Lyon R, Botha $\mathrm{K}$. The experience of and coping with abortion: A rapid review. The nature and dynamics of coping with induced abortion in young adult women. 2019:22.

20. Monti PM. Treating alcohol dependence: A coping skills training guide: Guilford Press; 2002.

21. Soetanto D. Networks and entrepreneurial learning: coping with difficulties. International Journal of Entrepreneurial Behavior \& Research. 2017.

22. Lafarge $C$, Mitchell $K$, Fox P. Termination of pregnancy for fetal abnormality: a meta-ethnography of women's experiences. Reproductive health matters. 2014;22(44):191-201.

23. Lotto R, Armstrong N, Smith LK. Care provision during termination of pregnancy following diagnosis of a severe congenital anomaly-A qualitative study of what is important to parents. Midwifery. 2016;43:14-20.

24. Lee EW, Denison FC, Hor K, Reynolds RM. Web-based interventions for prevention and treatment of perinatal mood disorders: a systematic review. BMC pregnancy and childbirth. 2016;16(1):38.

25. Swanson KM. Empirical development of a middle range theory of caring. Caring in Nursing Classics: An Essential Resource. 2012:211.

26. Korenromp M, Page-Christiaens G, Van Den Bout J, Mulder E, Hunfeld J, Potters C, et al. A prospective study on parental coping 4 months after termination of pregnancy for fetal anomalies. 
Prenatal Diagnosis. 2007;27(8):709-16.

27. Fisher J, Lafarge $C$. Women's experience of care when undergoing termination of pregnancy for fetal anomaly in England. Journal of Reproductive and Infant Psychology. 2015;33(1):69-87.

28. Bagheri L, Nazari AM, Chaman R, Ghiasi A, Motaghi Z. The Effectiveness of Healing Interventions for Post-Abortion Grief: A Systematic Review and Meta-Analysis. Iranian Journal of Public Health. 2020;49(3):426-36.

29. Fu MR, Axelrod D, Guth AA, Rampertaap K, El-Shammaa N, Hiotis K, et al. mHealth self-care interventions: managing symptoms following breast cancer treatment. Mhealth. 2016;2.

30. Connor KM, Davidson JR. Development of a new resilience scale: The Connor-Davidson resilience scale (CD-RISC). Depression and anxiety. 2003;18(2):76-82.

31. Mohammadi M. The study of key factors influences on resiliency of substance abuse at risk: PhD thesis. Tehran: University of Social Welfare and Rehabilitation Sciences 2005; 2005.

32. Samani S, Jokar B, Sahragard N. Effects of resilience on mental health and life satisfaction. Iranian Journal of psychiatry and clinical psychology. 2007;13(3):290-5.

33. Carver CS, Scheier MF, Weintraub JK. Assessing coping strategies: a theoretically based approach. Journal of personality and social psychology. 1989;56(2):267.

34. Zolfaghari f, Mohammadkhani $p$, Poorshahbaz a. Coping Strategies, Perceived Self-efficacy, and attitude toward Life events in the Normal and Neurotic Iranian Groups. Iranian Journal of Psychiatry and Clinical Psychology. 1998;3(3):43-54. eng.

35. Molazadeh J, Mansour M, EZHEHEI J, Kiamanesh A. COPING STYLES AND MARITAL ADJUSTMENT AMONG MARTYRS'CHILDREN. 2002:255-75.

36. jafari shalkoohi a, Asadi Majreh S, Akbari b. The effectiveness of mindfulness training on resiliency and cognitive emotion regulation strategies in pregnant women. Knowledge \& Research in Applied Psychology. 2020;21(2):43-53.

37. Afshari A. Comparison of the Efficacy of Acceptance and Commitment Therapy and Mind-Fullness Therapy on Women's Resilience in repeated Abortions. Iranian Journal of Psychiatric Nursing. 2018;6(2):11-8.

38. SEYEDFATEMI N, AHMADZAD ASL M, Bahrami R, HAGHANI H. The Effect of Virtual Social Network Based Psycho-Education on Resilience of the Family Caregivers of Clients with Severe Mental Disorders. IRANIAN JOURNAL OF PSYCHIATRIC NURSING (IJPN). 2019;6(6 \#f00580):-.

39. Sriarporn P, Turale S, Lordee N, Liamtrirat S, Hanpra W, Kanthino A. Support program for women suffering grief after termination of pregnancy: A pilot study. Nursing \& health sciences. 2017;19(1):75-80.

40. Heller HM, Hoogendoorn AW, Honig A, Broekman BF, van Straten A. The Effectiveness of a Guided Internet-Based Tool for the Treatment of Depression and Anxiety in Pregnancy (MamaKits Online): Randomized Controlled Trial. Journal of medical Internet research. 2020;22(3):e15172. 
41. Kersting A, Dölemeyer R, Steinig J, Walter F, Kroker K, Baust K, et al. Brief Internet-based intervention reduces posttraumatic stress and prolonged grief in parents after the loss of a child during pregnancy: a randomized controlled trial. Psychotherapy and Psychosomatics. 2013;82(6):372-81.

42. Fonseca A, Monteiro F, Alves S, Gorayeb R, Canavarro MC. Be a Mom, a web-based intervention to prevent postpartum depression: The enhancement of self-regulatory skills and its association with postpartum depressive symptoms. Frontiers in psychology. 2019;10.

43. Johnson OP, Langford RW. A randomized trial of a bereavement intervention for pregnancy loss. Journal of Obstetric, Gynecologic \& Neonatal Nursing. 2015;44(4):492-9.

44. Golmakani N, Ahmadi M, Asgharipour N, Esmaeli H. The Effect of Supportive care program on women's Bereavement with early Miscarriage. The Iranian Journal of Obstetrics, Gynecology and Infertility. 2017;20(8):33-41.

45. HAJNASIRI H, BEHBODIMOGHDDAM Z, GHASEMZADEH S, RANJKESH F, GERANMAYEH M. THE STUDY OF THE CONSULTATION EFFECT ON DEPRESSION AND ANXIETY AFTER LEGAL ABORTION. IRanian Journal of Psychiatric Nursing (IJPN). 2016;4(1):64-72.

46. Biggs MA, Neuhaus JM, Foster DG. Mental health diagnoses 3 years after receiving or being denied an abortion in the United States. American journal of public health. 2015;105(12):2557-63.

47. Duggal D, Sacks-Zimmerman A, Liberta T. The impact of hope and resilience on multiple factors in neurosurgical patients. Cureus. 2016;8(10).

48. Aghamiri N, Niknam M. The Effectiveness of Reality Therapy Training on Coping Strategies and Cognitive Distortions among Pregnant Women. Community Health (Salāmat-i ijtimāī). 2018;5(4):33845.

49. Mahdi MH, Haghayegh SA. Efficacy of group training of problem solving on resiliency, life satisfaction and coping strategy of families of substance abuse disorder. Rooyesh-e-Ravanshenasi. 2017;6(3):163-90. eng.

50. Rezaei E, Malekpour M, Oreyzi H. The Effect of the" Life-Skills" Training on the Stress and Youths' Stress Coping Methods in Pseudofamily Centers. Scientific Journal of Clinical Psychology \& Personality. 2009;1(34):21-8.

\section{Supplementary Files}

This is a list of supplementary files associated with this preprint. Click to download.

- Appendix.docx 